\title{
Granular Cell Tumor of the Sellar Region
}

National Cancer Institute

\section{Source}

National Cancer Institute. Granular Cell Tumor of the Sellar Region. NCI Thesaurus. Code C7017.

A generally benign intrasellar and/or suprasellar mass arising from the neurohypophysis or infundibulum. It is composed of nests of large cells with granular, eosinophilic cytoplasm due to abundant intracytoplasmic lysosomes. It generally has a slow progression and lacks invasive growth. (Adapted from WHO) 